\title{
Mesenchymal Stem Cells Induce Expression of CD73 in Human Monocytes In Vitro and in a Swine Model of Myocardial Infarction In Vivo
}

\section{OPEN ACCESS \\ Edited by: \\ Duncan Howie, \\ University of Oxford, \\ United Kingdom \\ Reviewed by: \\ Fabio Malavasi, \\ Università degli Studi \\ di Torino, Italy \\ Patrizia Ballerini, \\ Università degli Studi \\ "G. d'Annunzio" Chieti - \\ Pescara, Italy \\ *Correspondence: \\ Antoni Bayes-Genis \\ abayes@germanstrias. \\ gencat.cat; \\ Francesc E. Borràs \\ feborras@igtp.cat \\ ${ }^{+}$Co-first author.}

Specialty section: This article was submitted to Immunological Tolerance and

Regulation,

a section of the journal

Frontiers in Immunology

Received: 02 August 2017 Accepted: 02 November 2017 Published: 20 November 2017

Citation: Monguió-Tortajada M, Roura S, Gálvez-Montón C, Franquesa M, Bayes-Genis A and Borràs FE (2017)

Mesenchymal Stem Cells Induce

Expression of CD73 in Human

Monocytes In Vitro and in a

Swine Model of Myocardial Infarction In Vivo.

Front. Immunol. 8:1577. doi: 10.3389/fimmu.2017.01577

\author{
Marta Monguió-Tortajada ${ }^{1,2+}$, Santiago Roura ${ }^{3,4,5 t}$, Carolina Gálvez-Montón ${ }^{3,5}$, Marcella \\ Franquesa ${ }^{1,6}$, Antoni Bayes-Genis ${ }^{3,5,7,8 *}$ and Francesc E. Borràs ${ }^{1,2,6 *}$
}

${ }^{1}$ REMAR-IVECAT Group, Health Science Research Institute Germans Trias i Pujol, Badalona, Spain, ${ }^{2}$ Department of Cell Biology, Physiology and Immunology, Universitat Autònoma de Barcelona (UAB), Barcelona, Spain, ${ }^{3}$ CRREC Research Program, Health Science Research Institute Germans Trias i Pujol, Badalona, Spain, ${ }^{4}$ Center of Regenerative Medicine in Barcelona, Barcelona, Spain, ${ }^{5} \mathrm{CIBERCV}$, Instituto de Salud Carlos III, Madrid, Spain, ${ }^{6}$ Nephrology Service, Germans Trias i Pujol University Hospital, Badalona, Spain, ${ }^{7}$ Cardiology Service, Germans Trias i Pujol University Hospital, Badalona, Spain, ${ }^{8}$ Department of Medicine, Universitat Autònoma de Barcelona (UAB), Barcelona, Spain

The ectoenzymes CD39 and CD73 regulate the purinergic signaling through the hydrolysis of adenosine triphosphate (ATP)/ADP to AMP and to adenosine (Ado), respectively. This shifts the pro-inflammatory milieu induced by extracellular ATP to the anti-inflammatory regulation by Ado. Mesenchymal stem cells (MSCs) have potent immunomodulatory capabilities, including monocyte modulation toward an anti-inflammatory phenotype aiding tissue repair. In vitro, we observed that human cardiac adipose tissue-derived MSCs (CATMSCs) and umbilical cord MSCs similarly polarize monocytes toward a regulatory M2 phenotype, which maintained the expression of CD39 and induced expression of CD73 in a cell contact dependent fashion, correlating with increased functional activity. In addition, the local treatment with porcine cATMSCs using an engineered bioactive graft promoted the in vivo CD73 expression on host monocytes in a swine model of myocardial infarction. Our results suggest the upregulation of ectonucleotidases on MSC-conditioned monocytes as an effective mechanism to amplify the long-lasting immunomodulatory and healing effects of MSCs delivery.

Keywords: CD73, adenosine, immunomodulation, mesenchymal stem cell, ectonucleotidase, myocardial infarction, purigernic signaling, regeneration

\section{INTRODUCTION}

Exacerbated immune responses hamper solid organ transplantation and regeneration of injured tissues and lead to allergies, autoimmune diseases, and organ rejection. Antigen-presenting cells such as monocytes and dendritic cells (DCs) are responsible of linking the innate and adaptive phases of the immune response, providing signals to either trigger or downmodulate this response. Thus,

\footnotetext{
Abbreviations: Ab, antibody; Ado, adenosine; 5'AMP, adenosine 5'-monophosphate; ATP, adenosine triphosphate; cATMSCs, adipose tissue-derived MSCs; CD39, nucleoside triphosphate diphosphohydrolase; CD73, ecto-5'-nucleotidase; DAMPs, damage-associated molecular patterns; DAPI, 4',6-diamidino-2-phenylindole dihydrochloride; DC, dendritic cell; HGF, hepatic growth factor; HLA-G, human leukocyte antigen-G; HO-1, heme oxygenase-1; IDO, indoleamine 2,3-dioxygenase; IL6, interleukin 6; MDDC, monocyte-derived dendritic cell; MI, myocardial infarction; MSC, mesenchymal stem cell; NO, nitric oxide; PGE2, prostaglandin E2; TGF $\beta$, transforming growth factor- $\beta$; TNF $\alpha$, tumor necrosis factor $\alpha$; UCMSCs, umbilical cord MSCs.
} 
in some clinical settings, modulation of monocyte polarization and/or DC maturation is one of the key points to prevent an unwanted immune response.

The immune response can be specifically modulated by signals from the millieu, including cytokines, chemokines, and others such as purinergic mediators. Among them, adenosine triphosphate (ATP) promotes inflammation when it is found in high amounts during apoptosis and necrosis in damaged tissues (1-3); on the contrary, removal of extracellular ATP avoids exacerbated tissue inflammation. Extracellularly, ATP is sequentially hydrolyzed to $\mathrm{ADP}$ and $5^{\prime} \mathrm{AMP}$ by the ectoenzyme nucleoside triphosphate diphosphohydrolase (NTPD-1/ CD39) and to adenosine (Ado) by the ecto- $5^{\prime}$-nucleotidase (ecto-5'-NT/CD73) $(2,4)$. The final product, Ado, is a powerful anti-inflammatory purine nucleoside, which has been described to immunosuppress macrophages, DCs, natural killer (NK), T, and B cells to promote tolerance $(5,6)$. Therefore, ATP hydrolysis is not only beneficial to reduce the pro-inflammatory ATP levels but also to produce the anti-inflammatory Ado. CD73 expression has been linked to the regulatory phenotypes of $\mathrm{T}$ and NK cells (6-8), and it is also a cell marker for progenitor or mesenchymal stem cells (MSCs) (9).

Mesenchymal stem cells have been widely associated with both regenerative and immunomodulatory capabilities (10-12). For instance, MSCs derived from umbilical cord MSCs (UCMSCs) (i.e., Wharton's jelly) powerfully inhibit the inflammatory response of stimulated T cells (12). Also, cardiac adipose tissuederived MSCs (cATMSCs), which represent a mesenchymal-like cell population with intrinsic cardiomyogenic potential (13), abrogate $\mathrm{T}$ cell proliferation upon stimulation with allogeneic mature monocyte-derived DCs (14) and promote tissue repair and immune suppression in an in vivo model of myocardial infarction (MI) $(15,16)$.

Among a broad number of mechanisms of action, MSCs generally modulate monocyte polarization toward an anti-inflammatory M2 phenotype (17-19) and restrain DC differentiation, resulting in the inhibition of the host immune response (20-22). At the same time, different in vivo models have demonstrated the need for monocytes/macrophages modulation to achieve healing and tissue repair by MSC treatment $(19,23,24)$.

In this study, we first comparatively assess whether UCMSCs and cATMSCs (as distinct sources of MSCs) contribute to induce the functional expression of CD73 on monocytes, promoting the activation of their adenosinergic enzymatic activity. Finally, we evaluate the presence of infiltrated host monocytes expressing CD73 once cATMSCs are infused into swine post-infarcted myocardium.

\section{MATERIALS AND METHODS}

\section{Human CATMSC and UCMSC Isolation and Culture}

The study protocols were approved by the Clinical Research Ethics Committee of our institution (Comitè Ėtic d'Investigació Clínica, HuGTiP, Refs. CEIC: EO-10-13, EO-10-016 and EO-12-022), and conformed to the principles outlined in the
Declaration of Helsinki. Written informed consent was obtained from donors.

Human cATMSCs were extracted from adipose tissue surrounding the base of the heart and around the aortic root from patients undergoing cardiothoracic surgery prior to coronary artery bypass graft initiation $(n=6)$, as reported in Bayes-Genis et al. (13) and Perea-Gil et al. (14). In addition, fresh umbilical cords (UC, $n=6$ ) were obtained after birth and UCMSCs were isolated and cultured as reported in Monguió-Tortajada et al. (12).

\section{Monocyte Isolation}

Peripheral blood mononuclear cells were obtained from leukocyte residues from healthy donors from the Blood and Tissue Bank (Barcelona, Spain) $(n=22)$ by Ficoll Hypaque Pus ${ }^{\mathrm{TM}}$ density gradient centrifugation (GE Healthcare Biosciences) at 1,800 rpm for $30 \mathrm{~min}$, and $\mathrm{CD}^{+}$cells were depleted using the RosetteSep ${ }^{\mathrm{TM}}$ Human CD3 Depletion Cocktail (StemCell Technologies). Monocytes were then isolated using the EasySep ${ }^{\mathrm{TM}}$ Human anti-CD14 Positive Selection Kit (StemCell Technologies) or the MagniSort Human CD14 Positive Selection kit (eBioscience) following manufacturers' instructions. Recovered cells were counted using PerfectCount Microspheres (Cytognos) and assessed for purity $\left(>90 \% \mathrm{CD}^{+} 4^{+}\right.$) and viability [ $\geq 93 \%$ by FSC/ SSC and 7 $\mathrm{AAD}^{-}(\mathrm{BD})$ gating] in a Canto II flow cytometer (BD).

\section{Monocyte Differentiation to DCs}

Monocytes were cultured at $1 \times 10^{6}$ cells $/ \mathrm{ml}$ in complete medium composed of RMPI 1640 (Gibco) supplemented with $2 \mathrm{mM}$ L-glutamine (Sigma), $100 \mathrm{U} / \mathrm{ml}$ penicillin (Cepa), $100 \mu \mathrm{g} / \mathrm{ml}$ streptomycin (Normon Laboratories), 5\% human platelet lysate (Lonza), and DC differentiation cytokines: $300 \mathrm{IU} / \mathrm{ml} \mathrm{IL-4} \mathrm{and}$ $450 \mathrm{IU} / \mathrm{ml}$ GM-CSF (Miltenyi Biotech). After 6 days, monocytederived dendritic cells (MDDCs) were harvested, counted, and assessed for viability and differentiation by 7AAD and CD11c staining, respectively (both from BD).

\section{Monocyte and MDDC Conditioning}

Monocytes or MDDCs were cultured at $1 \times 10^{6}$ cells $/ \mathrm{ml}$ in a 20:1 ratio over a layer of cATMSCs or UCMSCs, which were previously let adhere to the culture plates for $4 \mathrm{~h}$. As a control, monocytes were cultured alone or in the presence of $500 \mathrm{ng} / \mathrm{ml}$ LPS (Sigma). Contact dependency was assessed using a 24-well transwell system with $0.4 \mu \mathrm{m}$-pore polycarbonate membrane (Costar). Monocytes $\left(4 \times 10^{5}\right)$ were seeded in each well and cATMSCs or UCMSCs $\left(2 \times 10^{4} ; 20: 1\right.$ ratio $)$ were applied to the upper chamber. Alternatively, monocytes were cultured in the presence of UCMSC conditioned media as published before (12).

After co-culture, monocytes or MDDCs were detached using accutase (Sigma) and washed with FACSFlow (BD) $+2 \%$ fetal bovine serum (FBS). Monocytes were stained with CD14-FITC and CD90-PE/Cy7 (BD) and separated by FACS in an Aria II sorter (BD). MDDCs were separated by FACS according to CD11c-Bv421+ (BD). Purity was always assured to be over $98 \%$. Monocytes and MDDC were then pelleted and frozen at $-80^{\circ} \mathrm{C}$ for whole RNA extraction.

Cell phenotype was assessed by incubation with CD11c-Bv421, CD14-FITC, CD25-PerCP/Cy5.5, CD39-Bv650, CD40-APC, 
CD73-PE, CD90-PE/Cy7, CD163-Bv711, CD206-PE-CF594 (BD), and/or CD80-PEVio770 (Miltenyi Biotech) or corresponding isotype control antibodies and acquisition in FACSCanto II and LSR Fortessa flow cytometers (BD). Analysis was performed using FlowJo X software.

\section{RNA Extraction and qPCR}

Whole RNA content was isolated from cells using the RNeasy Mini kit (Qiagen). cDNA was synthesized using random hexamers (Qiagen) and the iScriptTM One-Step RT-PCR Kit (BioRad Laboratories) according to the supplier's protocol. Analysis of the monocyte polarization markers expression was performed as described previously (12), using the primer sequences indicated in Table S1 in Supplementary Material. Alternatively, $8 \mu \mathrm{l}$ of cDNA was preamplified with the TaqManW PreAmp Master Mix Kit (Applied Biosystems) in a final volume of $50 \mu$ l. Subsequently, $15 \mu \mathrm{l}$ of preamplified cDNA were amplified in a final volume of $50 \mu \mathrm{l}$ containing $25 \mu \mathrm{l}$ TaqMan $2 \times$ Universal PCR Master Mix and $2 \mu \mathrm{l}$ of the following FAM-labeled primer/probes (Applied Biosystems): CD73 (Hs00169777_m1), CD90 (Hs00264235_s1), and 18S (Hs99999901_s1). Data from four independent experiments were collected and analyzed on the LightCyclerW 480 Real-Time PCR System (Roche); each sample was analyzed in duplicate. The difference in threshold cycle $2\left(-\Delta \Delta C_{t}\right)$ method was used to quantify the relative expression for each gene using $18 \mathrm{~S}$ as endogenous reference (25).

\section{Cytokine Determination}

The human IL10 and tumor necrosis factor $\alpha(\mathrm{TNF} \alpha)$ levels were measured in supernatants of $72 \mathrm{~h}$-cultured monocytes using commercial ELISA kits (U-Cytech) following the manufacturer's instructions.

\section{CD73 Enzyme Activity}

Either MSCs or FACS-sorted conditioned monocytes were washed three times with MES buffer [0.025 M MES (Sigma) in $0.9 \% \mathrm{NaCl}$ (Braun) $\mathrm{pH} 6.0$ ] and cultured at 50,000 cells/well in the presence or absence of 5'AMP (Sigma) and the CD39 inhibitor POM1 (Tocris) or CD73 inhibitor APCP (ADP analog; Sigma) when indicated. After $2 \mathrm{~h}$ at $37^{\circ} \mathrm{C}$, cells were centrifuged and supernatants harvested to freshly quantify Pi concentration using the malachite green phosphate colorimetric assay kit (BioVision), following the manufacturer's instructions. 5'AMP and APCP alone were confirmed to yield negative values, and $\mathrm{Pi}$ production was calculated as the subtraction $[\mathrm{Pi}]_{\text {cells }+5^{\prime} \mathrm{AMP}}-[\mathrm{Pi}]_{\text {cells alone. }}$ Alternatively, the $2 \mathrm{~h}$-supernatant was snap frozen at $-80^{\circ} \mathrm{C}$ and analyzed for Ado concentration using the Adenosine assay kit (BioVision), following the manufacturer's instructions.

\section{Animal Experimentation and Immunostaining}

All animal studies were approved by the local Animal Experimentation Unit Ethical Committee (no. ES 100370001499) and complied with all guidelines concerning the use of animals in research and teaching as defined by the Guide for the Care and Use of Laboratory Animals (NIH Publication No. 80-23, revised 1996). Allogeneic porcine cATMSCs were isolated from cardiac adipose biopsy samples (average 0.4-5.9 g) from pigs undergoing cardiac surgery $(n=5)$, and processed as previously described (15). Succinctly, tissue specimens were washed in phosphatebuffered saline to remove contaminating debris and red blood cells, and digested in $0.015 \%$ collagenase (Type II-B, SigmaAldrich) for $30 \mathrm{~min}$ at $37^{\circ} \mathrm{C}$ in gentle agitation. The collagenase was inactivated by dilution with $\alpha$-MEM containing $10 \%$ FBS, $2 \mathrm{mM}$ glutamine, $1 \%$ penicillin-streptomycin (Gibco Invitrogen Corp.) ( $\alpha$-MEM-FCS). The cell suspension was centrifuged for $10 \mathrm{~min}$ at $1,200 \times g$, and the pellet was resuspended in $\alpha$-MEMFCS and filtered through a $100-\mu \mathrm{m}$ mesh. Adhered cells were finally grown to subconfluence in $\alpha$-MEM supplemented with $10 \%$ FBS, and cultured under standard conditions.

Engineered bioactive graft generation and implantation, MI induction, and immunohistological analysis was performed as described in previous studies $(15,16)$. In brief, a decellularized human pericardium-derived scaffold embedded with GFP-labeled porcine cATMSCs (treated animals; $n=7$ ) or without cells (control animals; $n=7$ ) was implanted covering the ischemic area in Landrace $\times$ Large White pigs $30 \mathrm{~min}$ after MI induction. In addition, a group submitted to the engineered bioactive graft enriched with cATMSCs but without MI induction was included (sham animals; $n=3$ ). Animals were sacrificed after 30 days of follow-up.

Immunostaining was performed on cells grown in $\mu$-dishes with glass bottom (Ibidi) or $10-\mu \mathrm{m}$ myocardial sections against GFP, cardiac troponin I (Abcam), CD73, and CD163 (Novus Biologicals) Abs (1:100). Subsequently, secondary Abs (1:500) conjugated to Alexa Fluor 488, Alexa Fluor 594, Alexa Fluor 647 (Molecular Probes), Cy2 and Cy3 (Jackson ImmunoResearch Laboratories) were applied. Samples were finally counterstained with Atto 488-conjugated phalloidin (1:40) and/or 4',6-diamidino-2-phenylindole dihydrochloride $(1: 10,000)$ (Sigma), and analyzed under an Axio Observer $\mathrm{Z} 1$ confocal microscope (Zeiss). For $\mathrm{CD} 63^{+}$and $\mathrm{CD}^{+} 3^{+}$cell quantification, at least four different optical fields from each section were measured under Image-Pro Plus software (6.2.1 version; Media Cybernetics, Inc.).

\section{Statistical Analysis}

Values are expressed as mean + or \pm SD. Kolmogorov-Smirnov analysis was used to check for normality of data and appropriate statistical tests are indicated for each dataset. Analyses were performed using the Graphpad Prism (6.0 version) and SPSS (21.0.0.0 version) softwares, and differences were considered significant when $p<0.05$.

\section{RESULTS}

\section{Monocyte Polarization by cATMSCs and UCMSCs}

To investigate the effect of MSC conditioning, we first analyzed the capacity of different human MSCs to skew monocyte polarization in vitro. Monocytes were co-cultured for $48 \mathrm{~h}$ with either cATMSCs or UCMSCs, and LPS as a positive control of monocyte activation. After co-culture, monocytes $\left(\mathrm{CD} 14^{+} / \mathrm{CD} 90^{\mathrm{mid}}\right)$ were easily isolated from MSCs (CD14 $4^{\mathrm{dim}} / \mathrm{CD} 90^{\text {high }}$ ) by FACS according to both their CD14 expression and lower expression of CD90 
compared to MSCs (Figure 1A). Monocytes exhibited better viability when co-cultured with MSCs (Figure 1B).

Both cATMSC and UCMSCs managed to upregulate the M2 markers CD163, CD206, TGM2, and CCL18 in monocytes at the mRNA level (Figure S1 in Supplementary Material), while the M1 marker CD80 remained unchanged. On the contrary, LPS activation of monocytes led to the increased expression of CD80. The relative mRNA expression of all markers studied (Figure 1C), suggested that both MSCs were promoting an M2 phenotype in monocytes. This phenotype was further assessed by surface protein expression, and while CD80 was unchanged, CD163 and CD206 did increase when monocytes were co-cultured with MSCs (Figure 1D). Furthermore, the cytokine profile showed that MSCs promoted the secretion of IL10 by monocytes, while no TNF $\alpha$ was detected (Figure 1E). The increased IL10 mRNA transcription of sorted monocytes after co-culture with MSCs (Figure 1F) together with the undetectable IL10 in MSC's supernatants (data not shown) could attribute IL10 production to monocytes, further confirming an anti-inflammatory profile induced by MSC co-culture.

\section{Induction of CD73 Expression in Monocytes}

After confirming the M2 skewing capabilities of cATMSCs and UCMSCs toward monocytes, we next studied the expression of adenosinergic ectoenzymes on these cells.
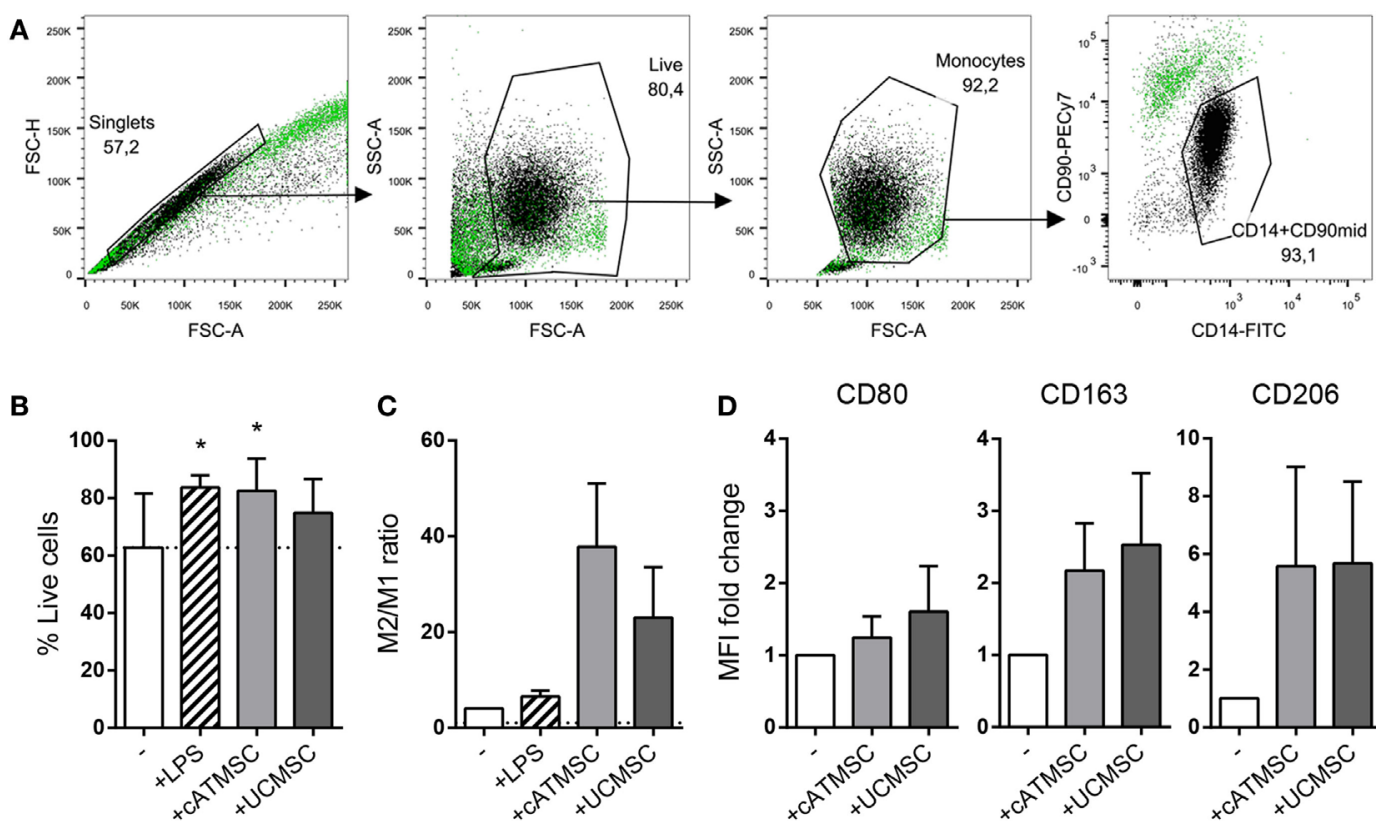

CD163

CD206
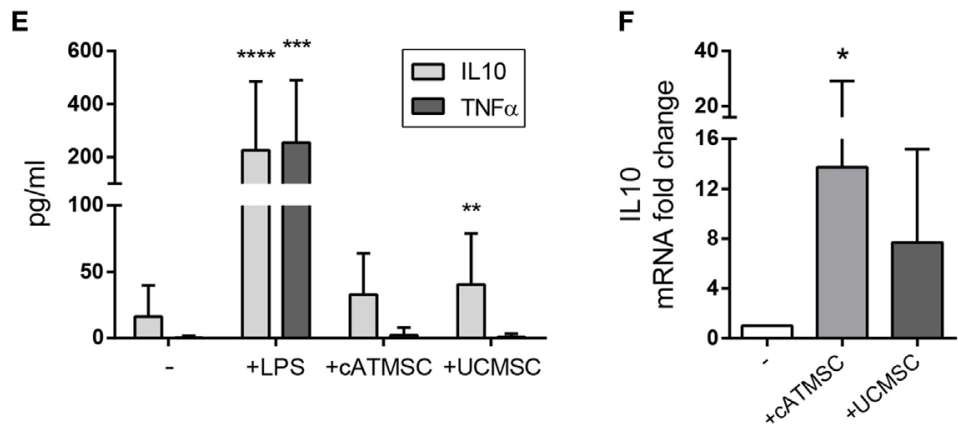

FIGURE 1 | CATMSCs and UCMSCs skew monocytes toward an "M2" phenotype. (A) Monocytes (CD14+/CD90mid) were separated by FACS after co-culture with CATMSCs or UCMSCs (CD14 dim/CD90 high). A representative gating analysis of monocytes co-cultured with UCMSCs (black dots) compared to UCMSCs alone (green dots) is shown. (B) Viability of co-cultured monocytes. Data are mean + SD of 11 independent experiments. (C) FACS-sorted monocytes were checked for the expression of M1 and M2 markers by GPCR after $48 \mathrm{~h}$ of co-culture. Data are expressed as mean $+\mathrm{SD}$ of the ratio between the M2 ( $\Sigma \mathrm{mRNA}$ fold change of CD163, CD206, TGM2, and CCL18) and M1 marker (mRNA fold change of CD80) depicted in Figure S1 in Supplementary Material. Data accounts for three independent experiments. (D) Fold increase in CD80, CD163, and CD206 MFI of monocytes cultured for $72 \mathrm{~h}$ with cATDPCs or UCMSCs, relative to monocytes alone (-). Data accounts for three independent experiments. (E) IL10 and TNF $\alpha$ cytokine levels in $72 \mathrm{~h}$-culture supernatants. Data are mean + SD of 12 independent experiments. Statistical differences are indicated where ${ }^{*} p<0.05$ by one-way ANOVA with Tukey's post hoc test compared to monocytes cultured alone $(-)$. (F) Fold increase in IL10 mRNA of monocytes cultured for $48 \mathrm{~h}$ with cATDPCs or UCMSCs, relative to monocytes alone (-). Data accounts for four independent experiments. cATMSCs, cardiac adipose tissue-derived MSCs; UCMSCs, umbilical cord MSCs; TNF $\alpha$, tumor necrosis factor $\alpha$. 
CD39 was already present in fresh blood peripheral blood monocytes (data not shown) and remained highly expressed on monocytes cultured alone or in the presence of LPS, cATMSCs, or UCMSCs (Figure 2).

Interestingly, monocytes cultured on a layer of both types of MSCs expressed higher levels of CD73 protein at 24 and $48 \mathrm{~h}$ of culture compared to control (Figure 3A). CD73 mRNA was incremented more than 500 times in monocytes after $48 \mathrm{~h}$ of co-culture with either cATMSCs or UCMSCs in comparison to cultured alone (Figure 3B), pointing to the induction of protein expression. Of note, LPS activation of monocytes also incremented CD73 expression. As a negative control, another classical MSC marker, CD90, was analyzed in conditioned monocytes. CD90 was found to be unchanged both at a protein and RNA levels (Figures 3C,D), suggesting the apparent specificity to CD73 acquisition and absence of a trogocytosis-like phenomenon.

As high levels of CD73 mRNA were detected after $48 \mathrm{~h}$ of conditioning, the CD73 protein expression and functional activity was further evaluated at $72 \mathrm{~h}$ of co-culture. Monocytes co-cultured with both cATMSCs and UCMSCs expressed higher levels of CD73 on the surface in comparison to control monocytes and LPS-stimulated monocytes (Figures 4A-C).

We also investigated whether direct cell contact between MSCs and monocytes was necessary to induce CD73 expression. For that purpose, co-culture experiments were performed using transwell culture plates, in which monocytes did not increase CD73 expression to the same extent compared to direct co-culture with MSCs (Figures 4B,C). To corroborate such observations, monocytes were cultured in the presence of MSC's conditioned medium (Figure S2 in Supplementary Material), which neither induced CD73 expression in monocytes.

\section{CD73 Induced in Conditioned Monocytes Is Functional}

The functionality of CD73 was then evaluated through the production of inorganic phosphate $(\mathrm{Pi})$ and Ado yielded from the hydrolysis of the CD73 substrate 5'AMP (Figure 4D). Confirming the high upregulation of CD73, MSC-co-cultured monocytes induced a much greater amount of $\mathrm{Pi}$ production compared to control and also LPS-stimulated monocytes (Figure 4E). Pi production was only detected when $5^{\prime}$ AMP was added to the cells, as an indication of CD73 action rather than from other ectoenzymes. Enzyme activity inhibition was also evaluated by using the ADP analog APCP. These experiments showed a dosedependent abrogation of $\mathrm{Pi}$ production by MSC-conditioned monocytes and a fully blocked Pi production in LPS-stimulated monocytes (Figure 4E).

In parallel experiments, CD73 enzyme functionality was also confirmed in CATMSCs and UCMSCs as a positive control. As expected by their higher CD73 expression, both cATMSCs and UCMSCs displayed a higher 5'AMP hydrolytic activity which was dose-dependently blocked with APCP (Figure S3 in Supplementary Material).

To further discard the production of Pi from other upstream hydrolysis, we checked the Pi concentration in the presence of the CD39 inhibitor POM1 (Figure 4F). Again, Pi was only produced in the presence of the CD73 substrate 5'AMP, and while POM1
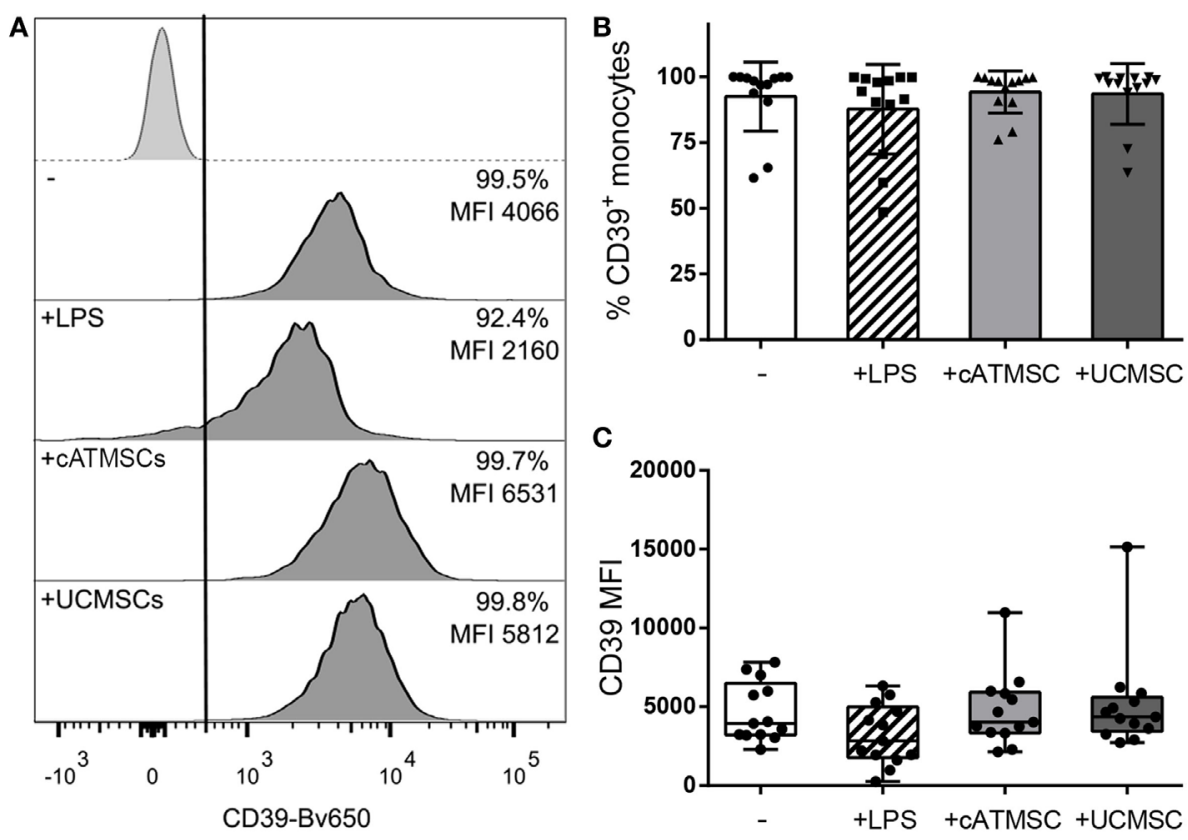

FIGURE 2 | CD39 expression is maintained in monocytes co-cultured with MSCs. (A) Representative histograms depicting the CD39 expression of monocytes cultured for $72 \mathrm{~h}$ alone (-) or with LPS, cATMSCs, or UCMSCs. The isotype control is depicted in the top row; the \% of positive cells and the MFI for the total monocyte population (CD14+/CD90 mid) are indicated in each plot. (B) Percentage of CD39+ and (C) CD39 MFI of monocytes cultured for $72 \mathrm{~h}$ alone (-) or with LPS, cATMSCs or UCMSCs. Data account for 12 independent experiments. cATMSCs, cardiac adipose tissue-derived MSCs; UCMSCs, umbilical cord MSCs. 

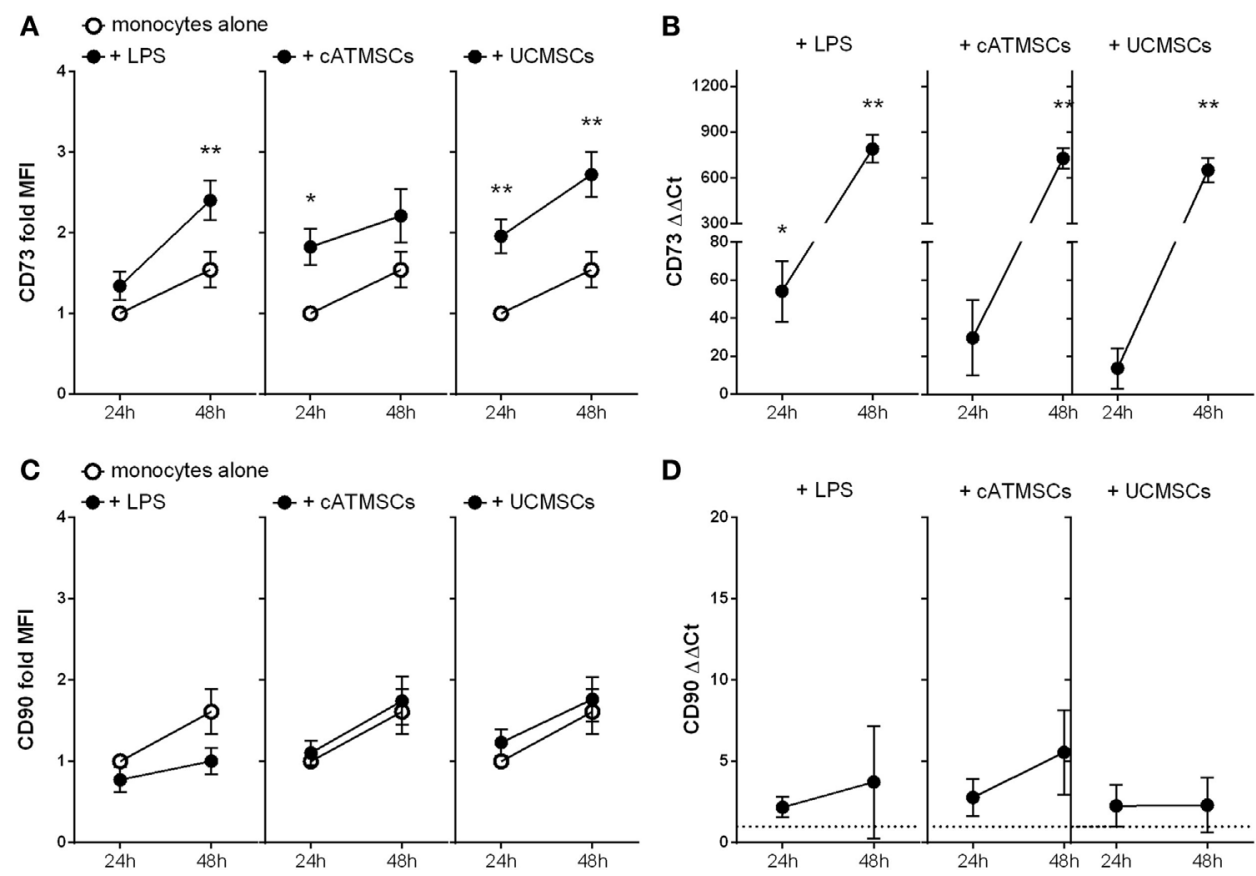

FIGURE 3 | CD73 is induced while CD90 remains unchanged in monocytes co-cultured with cATMSCs and UCMSCs. (A,C) Fold increase in CD73 and CD90 MFI of monocytes cultured for 24 or $48 \mathrm{~h}$ with LPS, ATDPCs, or UCMSCs (black dots), relative to 24 h-cultured monocytes alone (white dots). Statistical differences are indicated where ${ }^{*} p<0.05$ and ${ }^{* *} p<0.01$ by two-way ANOVA compared to monocytes cultured alone. (B,D) Fold increase in CD73 and CD90 mRNA ( $\left.\Delta \Delta C_{t}\right)$ of monocytes, relative to monocytes cultured alone. Statistical differences are indicated where ${ }^{*} p<0.05$; ${ }^{* *} p<0.01$; and ${ }^{* * *} p<0.001$ by one-sample $T$ test. Data are expressed as mean \pm SD and accounts for four independent experiments of different monocyte and MSC donors. MSC, mesenchymal stem cell; cATMSCs, cardiac adipose tissue-derived MSCs; UCMSCs, umbilical cord MSCs.

did not affect Pi production by MSC co-cultured monocytes, it was inhibited when APCP was added (Figure 4F).

We then confirmed the production of Ado by MSC cocultured monocytes, which was found in the supernatant only when 5'AMP was added to the monocytes and was abrogated by APCP addition (Figure 4G), indicating a CD73 functional enzymatic action.

\section{MDDCs Are Not Affected by MSC Conditioning}

In light of monocyte modulation by MSCs, we sought to explore the ability of MSCs to alter the maturation and CD73 expression of further differentiated cells such as MDDCs. Opposed to monocytes, the levels of CD73 and CD90 remained unchanged in MDDCs co-cultured with cATMSCs or UCMSCs (Figures 5A,B), which was confirmed as well by studying the mRNA levels of both CD markers (data not shown). On the other hand, MSCs failed to modulate MDDC maturation markers CD25 and CD40 (Figures 5C,D), which were upregulated to the same extent by LPS stimulation, regardless of MSC co-culture.

\section{Host Monocytes Acquire CD73 In Vivo in Swine Post-Infarcted Myocardium Treated with Porcine cATMSCs}

To investigate whether this in vitro effect occurred in vivo, we analyzed the presence of infiltrating monocytes and CD73 expression in a swine model of MI locally treated with porcine cATMSCs, previously reported by our group to reduce the amount of infiltrating effector $\mathrm{T}$ cells in the infarcted tissue and to ameliorate the regeneration of the myocardium $(15,16)$. In these studies, treated animals vs. controls experimented a significant reduction in infarct size $(3.4 \pm 0.6$ vs. $6.5 \pm 1 \%$; $p=0.015)$ and fibrosis in the infarct scar (collagen I/III ratio; $0.49 \pm 0.06$ vs. $1.66 \pm 0.5$; $p=0.019$ ), and improved in cardiac function (left ventricular ejection fraction; $7.5 \pm 4.9$ vs. $1.4 \pm 3.7 \%$; $p=0.038$, and stroke volume; $11.5 \pm 5.9$ vs. $3 \pm 4.5 \mathrm{ml} ; p=0.019$ ).

Mesenchymal stem cells were delivered in the ischemic area by the implantation of an allogeneic engineered bioactive graft comprising GFP-labeled porcine cATMSCs, compared to the use of an "empty" graft in control animals. In this study, 1 month after the implantation, we detected how $\mathrm{GFP}^{+}$cells (cATMSCs), expressing CD73 but not the monocyte marker CD163 (Figures 6A,B), actively migrated from the graft to the infarcted tissue and persisted within the damaged area in treated animals. Noticeably, treated, control, and sham animals had infiltrating monocytes $\left(\mathrm{CD} 163^{+}\right)$in the infarcted tissue (Figures 7A-C), but only in treated animals receiving cATMSCs after MI the infiltrating host monocytes gained CD73 expression. After quantification, no differences were found in the amount of $\mathrm{CD} 163^{+}$infiltrating monocytes between groups (Figure 7D). However, we could corroborate the gain on CD73 expression on host monocytes in treated vs. both control and sham animals in terms of absolute numbers $\left(3.95 \pm 2.45\right.$ vs. $1.12 \pm 0.66$ vs. $0.54 \pm 0.83 \mathrm{CD}^{+}{ }^{+}$ 


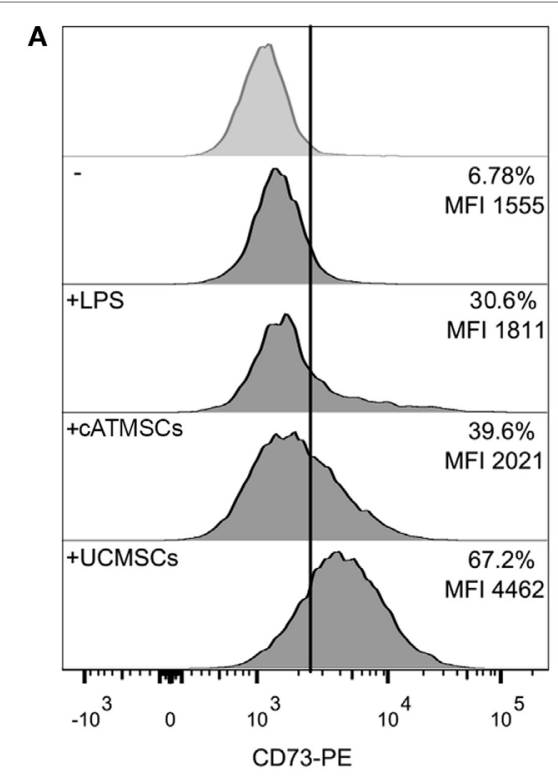

E

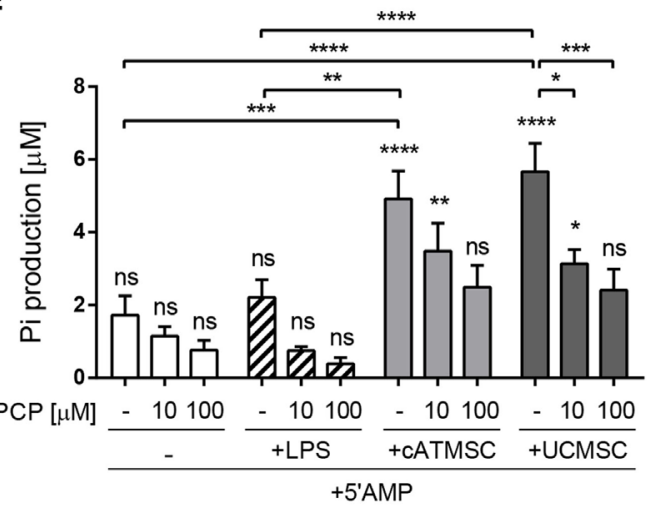

D
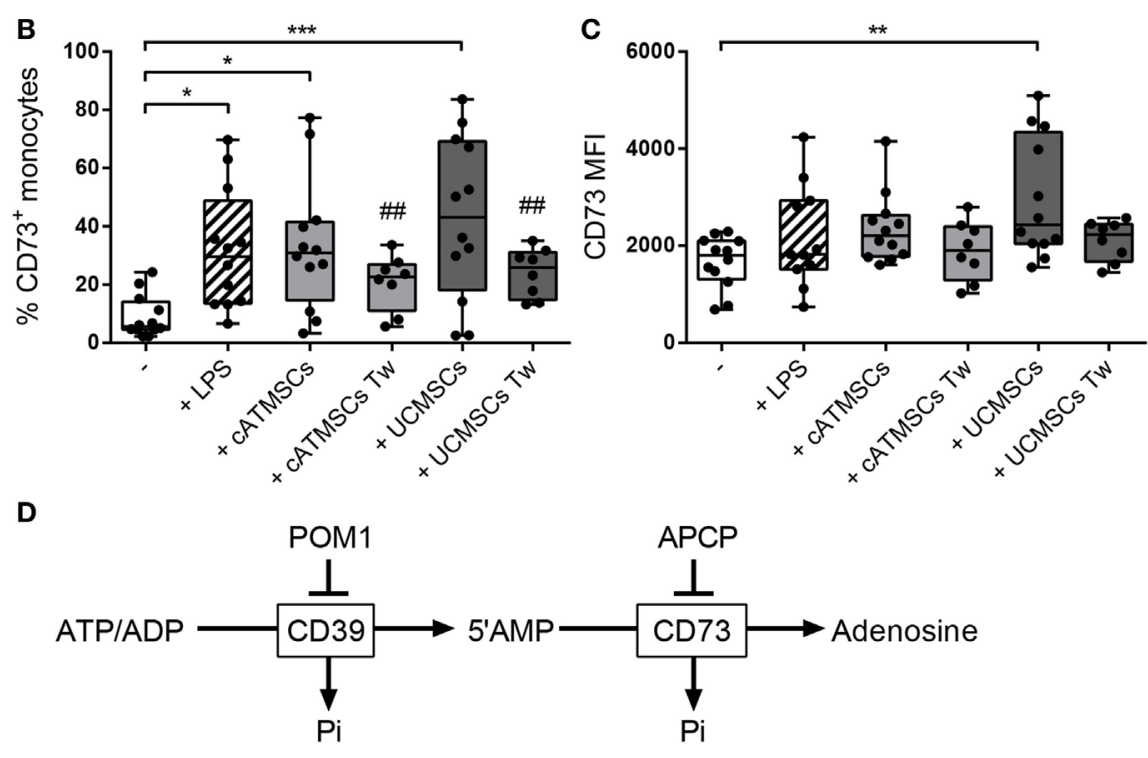

$\mathbf{F}$

G
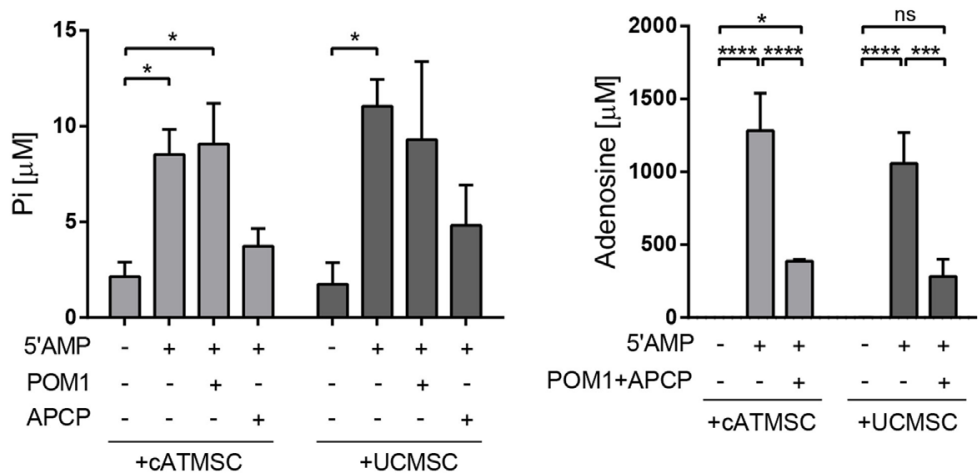

FIGURE 4 | Monocytes co-cultured with cATMSCs or UCMSCs upregulate the adenosinergic enzymatic activity. Monocytes cultured for $72 \mathrm{~h}$ alone (-) or with LPS, CATMSCs or UCMSCs were checked for CD73 surface expression and activity. (A) Representative histograms of CD73 expression. The isotype control is depicted in the top row; the $\%$ of positive cells and the MFI for the total monocyte population (CD14 $/$ CD90 mic) are indicated in each plot. (B) Percentage of CD73 ${ }^{+}$and (C) CD73 MFI of monocytes as mean \pm SD of 12 independent experiments. Tw: co-culture in transwell system. Statistical differences are indicated where ${ }^{*} p<0.05$, ${ }^{* *} p<0.01$, and ${ }^{* * *} p<0.001$ by one-way ANOVA with Tukey's post hoc analysis. (D) Schematic representation of the enzymatic hydrolysis of ATP/ADP to $5^{\prime}$ AMP by CD39 and to Ado by CD73, which can be inhibited by POM1 and APCP, respectively. Inorganic phosphate (Pi) is produced as a byproduct in each step. (E) Levels of inorganic phosphate (Pi) produced by FACS-sorted monocytes analyzed after the addition of the CD73 substrate (5'AMP; 1 mM) with or without the CD73 inhibitor (APCP). Data are presented in bars as the mean + SD concentration of Pi subtracted from the Pi present in monocytes without $5^{\prime}$ AMP. Data account for 9-13 independent experiments. $(\mathbf{F}, \mathbf{G})$ Levels of inorganic phosphate $(\mathrm{Pi}) \mathbf{( F )}$ and of Ado $(\mathbf{G})$ produced by FACS-sorted monocytes analyzed after the addition of the CD73 substrate (5'AMP; 1 mM) with or without the CD39 inhibitor (POM1) or the CD73 inhibitor (APCP). Data are presented in bars as the mean + SD concentration of Pi. Data accounts for four independent experiments. Statistical differences in each bar are compared to cells without 5 'AMP or to the indicated groups where ${ }^{\star} p<0.05,{ }^{\star \star} p<0.01,{ }^{\star \star \star *} p<0.001$, and ${ }^{\star \star \star \star} p<0.0001$ by two-way ANOVA with Tukey's post hoc analysis. cATMSCs, cardiac adipose tissue-derived MSCs; UCMSCs, umbilical cord MSCs; ATP, adenosine triphosphate; Ado, adenosine.

$\mathrm{CD} 163^{+}$cells; $p=0.028$ and $p=0.019$, respectively) $($ Figure $7 \mathrm{E})$, and also in the percentage of $\mathrm{CD}^{+} 3^{+}$out of $\mathrm{CD} 163^{+}$monocytes $(35 \pm 11$ vs. $8 \pm 6$ vs. $9 \pm 12 \% ; p=0.001$ and $p=0.0001$, respectively) (Figure 7F).

\section{DISCUSSION}

In this work, we demonstrate the molecular interplay between MSCs and monocytes and highlight the induction of the adenosinergic pathway on monocytes as an additional mechanism of immunomodulation and tissue healing. Particularly, we show that both human UCMSCs and human cATMSCs induce specifically in monocytes expression of the CD73 ectonucleotidase. By this function, together with the constitutive expression of CD39, monocytes would gain the ability to sequentially hydrolyze ATP to increase extracellular Ado concentration. Moreover, we corroborate this effect in vivo, as the local delivery of porcine cATMSCs into post-infarcted swine myocardium effectively 

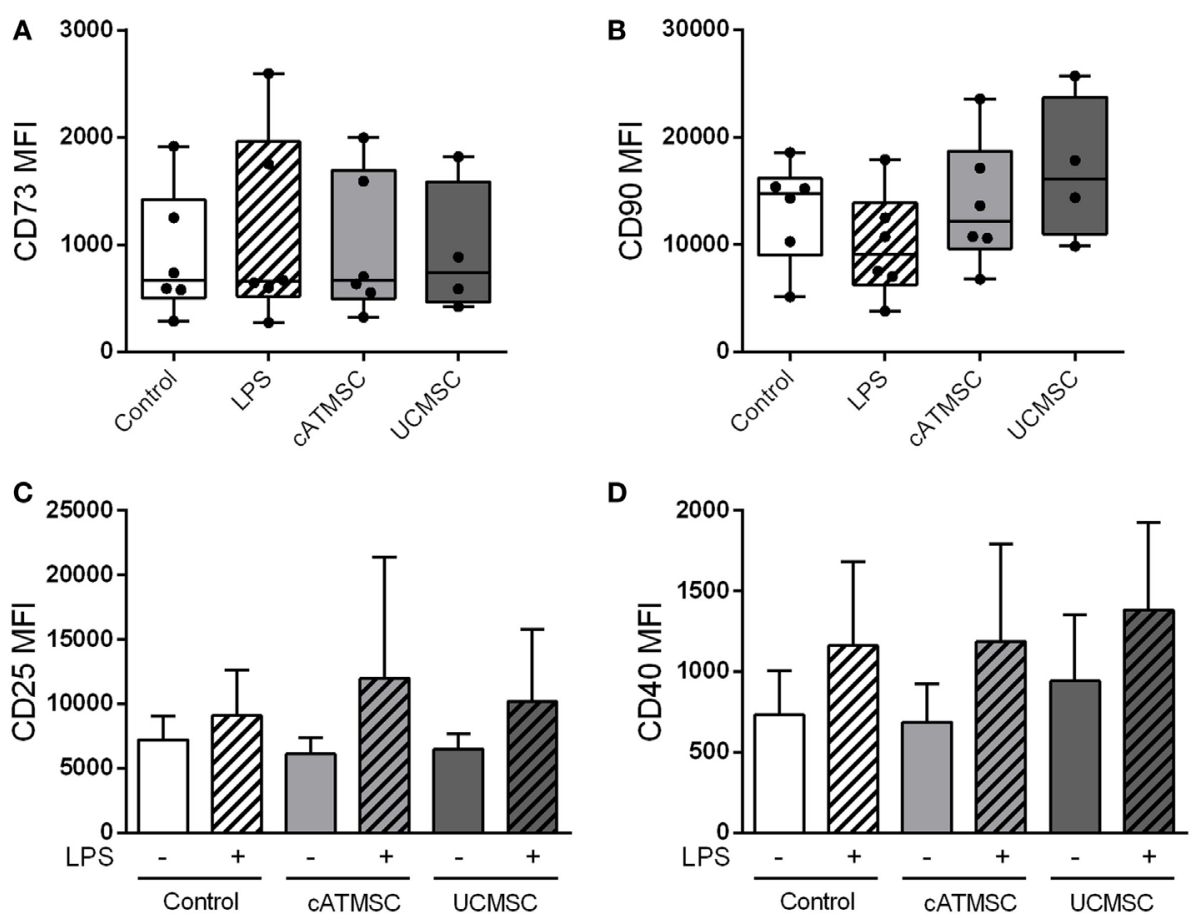

FIGURE 5 | CD73 and CD90 are not induced by MSC co-culture in MDDCs. (A,B) CD73 and CD90 MFI of MDDCs cultured for 48 h alone or with LPS, ATDPCs, or UCMSCs. (C,D) MFI values of the maturation markers CD25 and CD40 of MDDCs cultured for $48 \mathrm{~h}$ with or without CATMSCs or UCMSCs, and further stimulated with LPS (dashed bars) or not. Data are expressed as mean + SD and accounts for six independent experiments. MSC, mesenchymal stem cell; cATMSCs, cardiac adipose tissue-derived MSCs; UCMSCs, umbilical cord MSCs; MDDCs, monocyte-derived dendritic cells.

resulted into the expression of CD73 on infiltrating host monocytes, fostering an anti-inflammatory milieu.

The degradation of exogenous pro-inflammatory ATP into anti-inflammatory Ado has been attributed a key role for the control of inflammation in the local environment, and also to have systemic effects $(5,6,26,27)$. Ado reduces NK, macrophage, dendritic, B and T cells activation (4, 28-30), neutrophil accumulation (31), while promotes the generation of M2 macrophages and expansion of regulatory T cells $\left(\mathrm{CD} 39^{+} / \mathrm{CD}^{+} 3^{+}\right)$, thus establishing an adenosinergic amplification loop $(5,32-35)$. It further proves to be a powerful systemic immunosuppressant as Ado production is used as an immune evasion strategy by pathogens (36-38) and cancer cells $(8,39,40)$, and its accumulation leads to a severe combined immunodeficiency in patients lacking ADA for Ado degradation $(41,42)$. Remarkably, Ado production also helps in wound healing and tissue repair (43), as inhibits post-hypoxic vascular leakage (44) and promotes angiogenesis via VEGF production by macrophages (45). These effects have been proven in vivo, where increased Ado levels reduced necrotic injury and edema formation, and limited infarct size in a mouse and swine models of MI $(46,47)$.

The presence of the purinergic ectoenzymes CD39/CD73 has been described for different organs and cell types. For instance, while MSCs and endothelial cells display a constitutive expression $(48,49)$, CD39/CD73 are triggered upon cell activation in the generation of Tregs, whereas CD73 is reduced in activated B cells (50). MSCs have also been shown to induce CD73 expression in NK cells, although to a much lesser extent than we observed in monocytes (7). In our experiments, we interestingly observed that LPS stimulation of TLR4 incremented CD73 expression in monocytes, probably as a balancing mechanism of cell activation, as was observed in mouse before $(45,51)$. However, only MSC co-culture lead to sustained CD73 expression and to active 5'AMP hydrolysis by these cells, in a mechanism dependent of cell contact. Monocytes were polarized by both cATMSCs and UCMSCs toward an anti-inflammatory M2-like phenotype and to secrete immunomodulatory cytokines (IL10, CCL18) $(17,52$, $53)$, but it is worth to mention that other M2 switches such as the classical "M2A" induction by IL4 does not promote CD73 upregulation (54).

These observations are important given the reported short lifespan of MSCs after infusion in vivo. Once injected i.v., MSCs get trapped in the lung barrier because of their big size and are removed by monocytes/macrophages within hours (55-58), thus theoretically impeding the action of MSCs in the target tissue. Nevertheless, MSCs still promote a long-lasting systemic immunosuppressive effect for the resolution of inflammation and regeneration of wounded tissue. These effects could be firstly mediated temporarily by paracrine mediators, but secondarily by the modulation of the host's immune cells. In this sense, soluble molecules such as interleukin 6, prostaglandin E2, transforming growth factor- $\beta$, indoleamine 2,3-dioxygenase, hepatic growth factor, human leukocyte antigen-G, TSG6, and extracellular vesicles have been attributed to promote such paracrine effects $(12,58,59)$. Moreover, given that MSCs express CD39 and CD73 constitutively, Ado production is also part of MSC's paracrine 
A
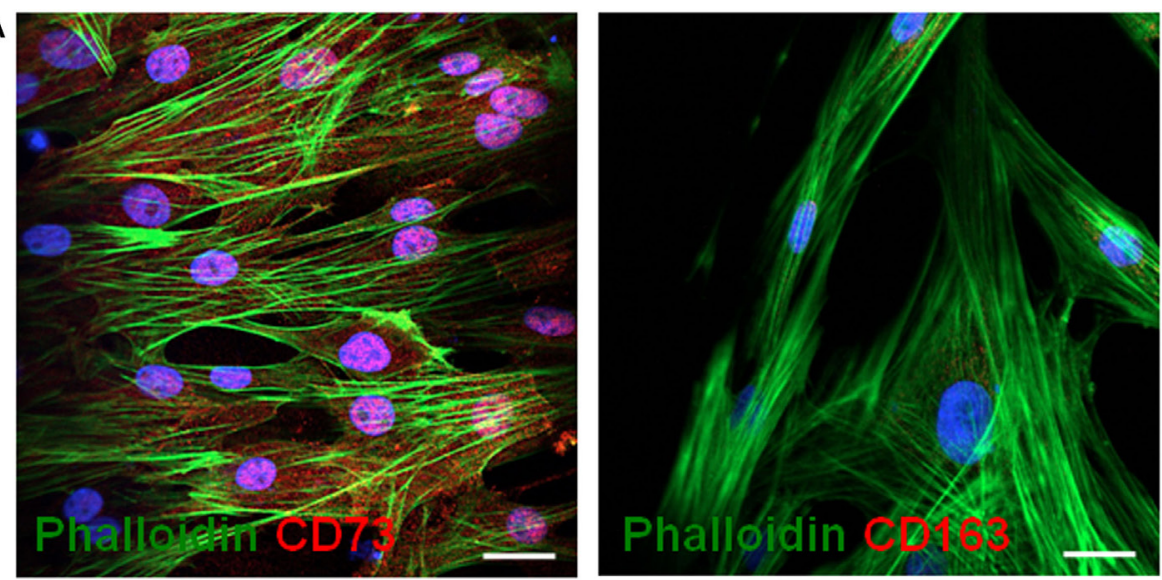

B
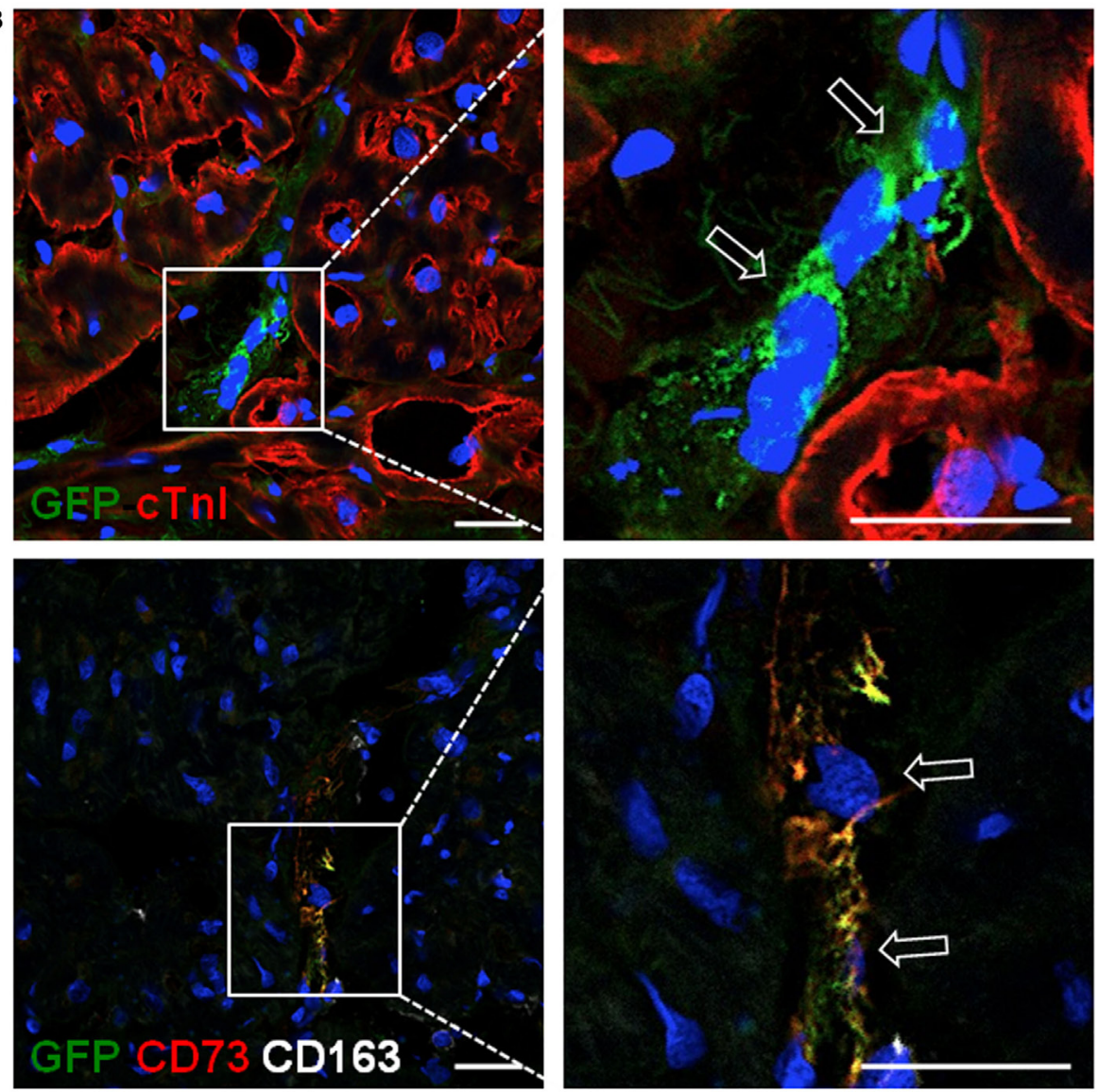

FIGURE 6 | Allogeneic cATMSCs migrated to the infarcted myocardium after graft implantation in swine. Representative confocal microscope images showing (A) porcine cATMSCs in in vitro culture or (B) sections within the infarcted myocardium. (A) Porcine cATMSCs are positive for CD73 (left, red) and negative for CD163 (right, red). (B) Presence of GFP+ porcine cATMSCs (empty arrows) in post-infarcted myocardium, also positive for CD73 but negative for CD163 (lower panels). Cell morphology, cardiac muscle, and cell nuclei are also counterstained using Atto 488-phalloidin, anti-cTnl Ab, and DAPI, respectively. Scale bars $=50 \mu \mathrm{m}$. cATMSCs, cardiac adipose tissue-derived MSCs; DAPI, 4',6-diamidino-2-phenylindole dihydrochloride.

immunosuppressive activity. In fact, CD73 itself can also have systemic effects as it can be both shed from the membrane and act in its soluble form (60-62) and also be released within extracellular vesicles, as proved by Amarnath et al. in an animal model of Th1 inflammation treated with infused MSCs, in which systemic
Ado production by released CD73 mediated the resolution of inflammation (63).

Following these MSC paracrine primary immunomodulatory effects, MSCs may modulate the action of immune cells for the generation of regulatory environments. Monocytes, which are 

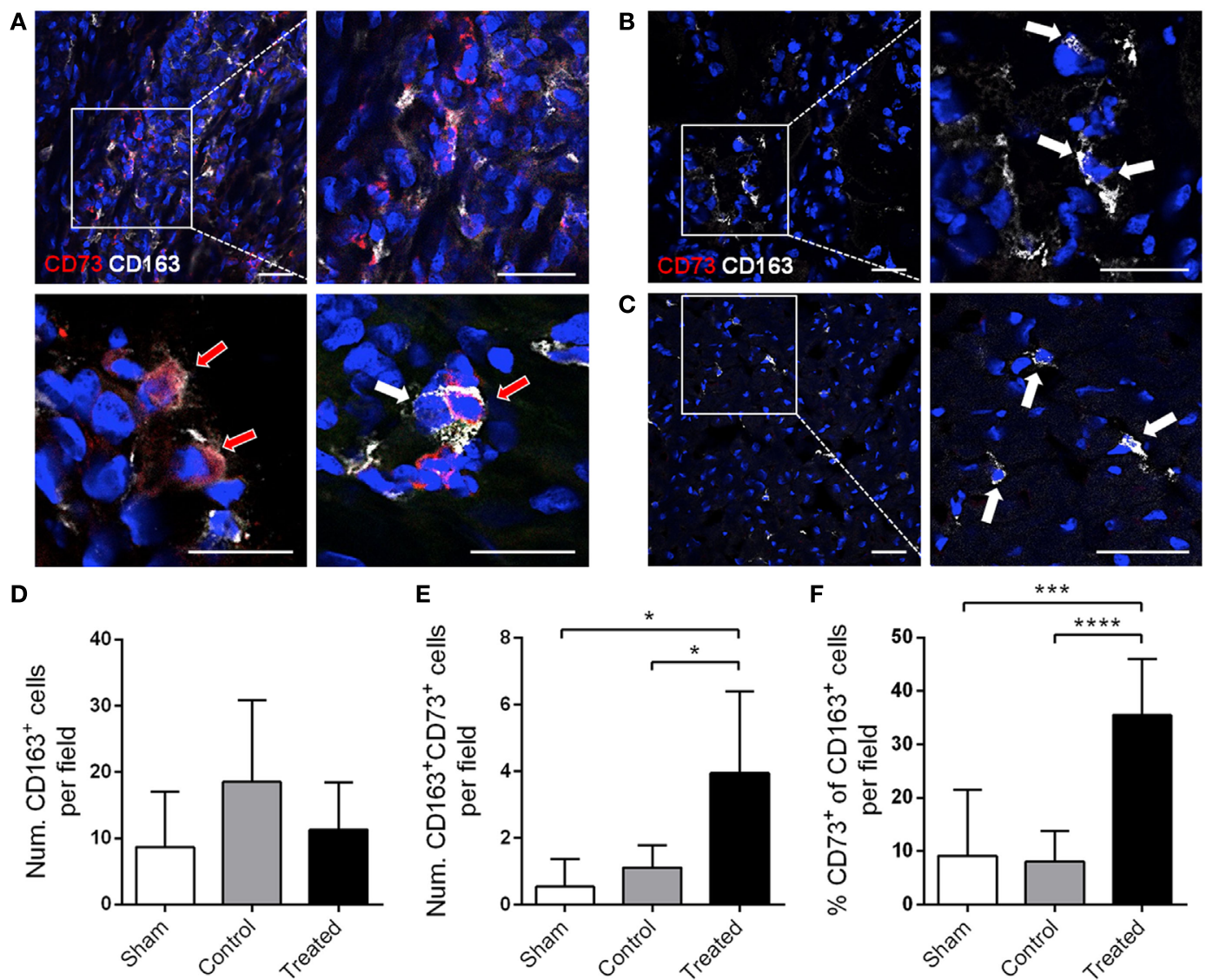

FIGURE 7 | CD73 is also induced in vivo in host monocytes in swine post-infarcted myocardium treated with porcine cATMSCs. (A-C) Infiltrating CD163+ monocytes (white arrows), some of them expressing CD73 (red arrows) in a cATMSC-treated animal (A), and CD163+ monocytes (white arrows) in a control (B) and sham (C) animals, both negative for CD73. CD73 is shown in red and CD163 in white, and nuclei are counterstained with DAPI in blue. Scale bars $=50 \mu \mathrm{m}$. (D,E) Histograms showing the number of CD163+ monocytes (D), CD73+ CD163+ monocytes (E) per optical field in all studied groups. (F) Percentage of CD73+ monocytes out of the CD163+ monocytes. Differences in immunohistochemical quantifications were compared using one-way ANOVA for multiple comparisons, with Tukey's test for the post hoc analysis. cATMSCs, cardiac adipose tissue-derived MSCs; DAPI, 4',6-diamidino-2-phenylindole dihydrochloride.

present in great numbers especially in the lungs, would interact with the infused MSCs and acquire an M2-like phenotype, including CD73 mRNA expression in less than $24 \mathrm{~h}$, as shown by our results. These $\mathrm{CD} 39^{+} / \mathrm{CD} 3^{+}$monocytes are fit to easily go through the lung barrier and migrate to the inflamed tissue to promote in situ immunomolulation and healing. Although the level of CD73 activity was much higher in MSCs, CD39 ${ }^{+} \mathrm{CD}^{+} 3^{+}$ monocytes would have the advantage of migration and delivering a targeted local effect.

At the same time, when MSCs are delivered directly to the injured tissue, they can regulate monocyte function locally, which are, together with granulocytes, the first cells to infiltrate into inflamed tissue (64). Remarkably, we previously demonstrated the use of a scaffold of decellularized human pericardium for the local delivery of porcine cATMSCs to the post-MI injured tissue. MSC treatment attained in vivo attenuation of inflammation (i.e., fewer activated $\mathrm{T}$ cells) and promoted the regeneration of the damaged myocardial tissue in post-infarcted pigs (16). Here, we also show the acquisition of CD73 expression by infiltrated host monocytes in MSC-treated animals, thus establishing an adenosinergic positive loop. The gain in CD73 by host monocytes was dependent on the combination of monocyte activation in response to pro-inflammatory damage-associated molecular patterns released after MI and the modulation by cATMSCs contained within the graft, given that both control and sham animals lacked presence of CD73 in monocytes.

This finding agrees with those reported by others confirming that collaboration with monocytes has been found to be essential for MSCs activity, from immunomodulation and Treg generation $(17,65)$ to stopping infiltration and aiding in the regeneration of inflamed tissue $(19,23,24,66)$.

Noteworthy, since the in vitro co-culture setting and the in vivo local administration of MSCs hinders the distinction between monocyte- and MSC-derived soluble CD73, we did not check for presence of soluble CD73, which is a limitation of our study. This might be underestimating the upregulation in CD73 protein expression by monocytes and thus could explain in part the differences between the mRNA and protein fold increase found in monocytes. 
Our functional experiments were focused to check the functionality of CD73 upregulation on MSC-conditioned monocytes. Therefore, we studied the last enzymatic step of extracellular Ado production mediated by the ectonucleotidase CD73. Pi and Ado levels did not increase in the absence of 5'AMP, and their production was only affected by APCP while not by POM1. Thus, Pi and Ado production could be attributed to CD73-mediated 5'AMP hydrolysis and discarded the action of other ectoenzymes such as CD39 or Pi release due to FACS-related sheer stress, as all cells underwent the same FACS separation.

We exclusively analyzed the presence of the ectoenzymes mediating the canonical pathway of Ado production, given that ATP would be incremented and readily available in sites of injury and inflammation such as a post-MI tissue. Nevertheless, other enzymatic pathways leading to the extracellular availability of $5^{\prime} \mathrm{AMP}$, such as the conversion of $\mathrm{NAD}^{+}$by CD38/ CD203a (67) may be also playing a part in MSC-conditioned monocytes.

Finally, studies on the modulation by MSC of further differentiated cells such as DCs have been proven controversial. Most studies describe MSCs able to modulate DC biology specially when added early in the differentiation process. However, in line with our observations, some authors report no effect of MSCs on later steps of differentiation or maturation process $(20,21)$. This seems to indicate that the MSC modulation would preferentially act on non-activated cells.

In summary, the upregulation of CD73 in MSC-conditioned monocytes emerges as an additional potential mechanism supporting the long-lasting immunomodulatory and healing effects of MSCs delivery. A better understanding of the signaling pathways triggered in monocytes by MSCs will help to better define new therapies for tissue injury and regenerative medicine.

\section{ETHICS STATEMENT}

The study protocols were approved by the Clinical Research Ethics Committee of our institution (Comitè Ètic d'Investigació Clínica, HuGTiP, Refs. CEIC: EO-10-13, EO-10-016 and EO-12-022), and conformed to the principles outlined in the Declaration of Helsinki. Written informed consent was obtained from donors.

\section{REFERENCES}

1. Mizumoto N, Kumamoto T, Robson SC, Sévigny J, Matsue H, Enjyoji K, et al. CD39 is the dominant Langerhans cell-associated ecto-NTPDase: modulatory roles in inflammation and immune responsiveness. Nat Med (2002) 8(4):358-65. doi:10.1038/nm0402-358

2. Antonioli L, Pacher P, Vizi ES, Haskó G. CD39 and CD73 in immunity and inflammation. Trends Mol Med (2013) 19(6):355-67. doi:10.1016/j. molmed.2013.03.005

3. Murphy PS, Wang J, Bhagwat SP, Munger JC, Janssen WJ, Wright TW, et al. CD73 regulates anti-inflammatory signaling between apoptotic cells and endotoxin-conditioned tissue macrophages. Cell Death Differ (2017) 24(3):559-70. doi:10.1038/cdd.2016.159

4. Haskó G, Cronstein B. Regulation of inflammation by adenosine. Front Immunol (2013) 4:85. doi:10.3389/fimmu.2013.00085

\section{AUTHOR CONTRIBUTIONS}

MM-T, SR, and FB designed the study; MM-T, SR and CG-M performed the experiments; MM-T, SR, CG-M, MF, and FB analyzed and interpreted the data; $\mathrm{MF}$ and $\mathrm{AB}-\mathrm{G}$ gave conceptual advice; MM-T, SR, and FB wrote the manuscript; AB-G and FB: final approval of the manuscript. All authors reviewed the manuscript.

\section{ACKNOWLEDGMENTS}

We thank the IGTP Flow Cytometry Core Facility and staff (Marco A. Fernández and Gerard Requena) for their contribution to this publication.

\section{FUNDING}

This work was supported in part by Grants from Fondo de Investigación Sanitaria, Instituto de Salud Carlos III (FIS PI14/01682), Generalitat de Catalunya (2014SGR804 and 2014SGR699, PERIS SLT002/16/00234), ISCIII-REDinREN (16/0009 Feder Funds), MINECO (SAF2014-59892-R), Fundació La Marató TV3 (201502 and 201516), Red de Terapia Celular-TerCel (RD16/00111/0006), CIBER Cardiovascular (CB16/11/00403), Societat Catalana de Cardiologia, and Fundació Bancària La Caixa. This work has been developed in the context of CERCA Programme (Generalitat de Catalunya) and AdvanceCat with the support of ACCIÓ (Catalonia Trade \& Investment; Generalitat de Catalunya) under the Catalan ERDF operational program (European Regional Development Fund) 2014-2020. MM-T is sponsored by a Grant (2014FI B00649) from the "Agència de Gestió d'Ajuts Universitaris i de Recerca" (AGAUR) and MF is sponsored by the PERIS contract (SLT002/16/00069), both from the Generalitat de Catalunya. FEB is a researcher from Fundació Institut de Recerca en Ciències de la Salut Germans Trias i Pujol supported by the Health Department of the Catalan Government (Generalitat de Catalunya).

\section{SUPPLEMENTARY MATERIAL}

The Supplementary Material for this article can be found online at http://www.frontiersin.org/article/10.3389/fimmu.2017.01577/ full\#supplementary-material.

5. Ohta A, Sitkovsky M. Extracellular adenosine-mediated modulation of regulatory T cells. Front Immunol (2014) 5:304. doi:10.3389/fimmu.2014.00304

6. Regateiro FS, Cobbold SP, Waldmann H. CD73 and adenosine generation in the creation of regulatory microenvironments. Clin Exp Immunol (2013) 171(1):1-7. doi:10.1111/j.1365-2249.2012.04623.x

7. Chatterjee D, Tufa DM, Baehre H, Hass R, Schmidt RE, Jacobs R. Natural killer cells acquire CD73 expression upon exposure to mesenchymal stem cells. Blood (2014) 123(4):594-5. doi:10.1182/blood-2013-09-524827

8. Beavis PA, Stagg J, Darcy PK, Smyth MJ. CD73: a potent suppressor of antitumor immune responses. Trends Immunol (2012) 33(5):231-7. doi:10.1016/j. it.2012.02.009

9. Dominici M, Le Blanc K, Mueller I, Slaper-Cortenbach I, Marini F, Krause D, et al. Minimal criteria for defining multipotent mesenchymal stromal cells. The International Society for Cellular Therapy position statement. Cytotherapy (2006) 8(4):315-7. doi:10.1080/14653240600855905 
10. Le Blanc K, Mougiakakos D. Multipotent mesenchymal stromal cells and the innate immune system. Nat Rev Immunol (2012) 12(5):383-96. doi:10.1038/ nri3209

11. Roura S, Soler-Botija C, Bagó JR, Llucià-Valldeperas A, Férnandez MA, Gálvez-Montón $\mathrm{C}$, et al. Postinfarction functional recovery driven by a three-dimensional engineered fibrin patch composed of human umbilical cord blood-derived mesenchymal stem cells. Stem Cells Transl Med (2015) 4(8):956-66. doi:10.5966/sctm.2014-0259

12. Monguió-Tortajada M, Roura S, Gálvez-Montón C, Puja JM, Aran G, Sanjurjo L, et al. Nanosized UCMSC-derived extracellular vesicles but not conditioned medium exclusively inhibit the inflammatory response of stimulated T cells: implications for nanomedicine. Theranostics (2017) 7(2):270-84. doi:10.7150/thno. 16154

13. Bayes-Genis A, Soler-Botija C, Farré J, Sepúlveda P, Raya A, Roura S, et al. Human progenitor cells derived from cardiac adipose tissue ameliorate myocardial infarction in rodents. J Mol Cell Cardiol (2010) 49(5):771-80. doi:10.1016/j.yjmcc.2010.08.010

14. Perea-Gil I, Monguió-Tortajada M, Gálvez-Montón C, Bayes-Genis A, Borràs FE, Roura S. Preclinical evaluation of the immunomodulatory properties of cardiac adipose tissue progenitor cells using umbilical cord blood mesenchymal stem cells: a direct comparative study. Biomed Res Int (2015) 2015:439808. doi:10.1155/2015/439808

15. Prat-Vidal C, Gálvez-Montón C, Puig-Sanvicens V, Sanchez B, DíazGüemes I, Bogónez-Franco P, et al. Online monitoring of myocardial bioprosthesis for cardiac repair. Int J Cardiol (2014) 174(3):654-61. doi:10.1016/j. ijcard.2014.04.181

16. Gálvez-Montón C, Bragós R, Soler-Botija C, Díaz-Güemes I, Prat-Vidal C, Crisóstomo $\mathrm{V}$, et al. Noninvasive assessment of an engineered bioactive graft in myocardial infarction: impact on cardiac function and scar healing. Stem Cells Transl Med (2017) 6(2):647-55. doi:10.5966/sctm.2016-0063

17. Melief SM, Schrama E, Brugman MH, Tiemessen MM, Hoogduijn MJ, Fibbe WE, et al. Multipotent stromal cells induce human regulatory $\mathrm{T}$ cells through a novel pathway involving skewing of monocytes toward anti-inflammatory macrophages. Stem Cells (2013) 31(9):1980-91. doi:10.1002/ stem. 1432

18. Cutler AJ, Limbani V, Girdlestone J, Navarrete CV. Umbilical cord-derived mesenchymal stromal cells modulate monocyte function to suppress $\mathrm{T}$ cell proliferation. JImmunol (2010) 185(11):6617-23. doi:10.4049/ jimmunol.1002239

19. Ben-Mordechai T, Holbova R, Landa-Rouben N, Harel-Adar T, Feinberg MS, Elrahman IA, et al. Macrophage subpopulations are essential for infarct repair with and without stem cell therapy. J Am Coll Cardiol (2013) 62(20):1890-901. doi:10.1016/j.jacc.2013.07.057

20. Spaggiari GM, Abdelrazik H, Becchetti F, Moretta L. MSCs inhibit monocyte-derived DC maturation and function by selectively interfering with the generation of immature DCs: central role of MSC-derived prostaglandin E2. Blood (2009) 113(26):6576-83. doi:10.1182/blood-2009-02-203943

21. Nauta AJ, Kruisselbrink AB, Lurvink E, Willemze R, Fibbe WE. Mesenchymal stem cells inhibit generation and function of both CD34+-derived and monocyte-derived dendritic cells. J Immunol (2006) 177(4):2080-7. doi:10.4049/ jimmunol.177.4.2080

22. Jiang XX, Zhang Y, Liu B, Zhang SX, Wu Y, Yu XD, et al. Human mesenchymal stem cells inhibit differentiation and function of monocyte-derived dendritic cells. Blood (2005) 105(10):4120-6. doi:10.1182/blood-2004-02-0586

23. Blázquez R, Sánchez-Margallo FM, Álvarez V, Usón A, Casado JG. Surgical meshes coated with mesenchymal stem cells provide an anti-inflammatory environment by a M2 macrophage polarization. Acta Biomater (2016) 31:221-30. doi:10.1016/j.actbio.2015.11.057

24. Dayan V, Yannarelli G, Billia F, Filomeno P, Wang XH, Davies JE, et al. Mesenchymal stromal cells mediate a switch to alternatively activated monocytes/macrophages after acute myocardial infarction. Basic Res Cardiol (2011) 106(6):1299-310. doi:10.1007/s00395-011-0221-9

25. Livak KJ, Schmittgen TD. Analysis of relative gene expression data using real-time quantitative PCR and the $2-\Delta \Delta \mathrm{CT}$ method. Methods (2001) 25(4):402-8. doi:10.1006/meth.2001.1262

26. Schenk U, Frascoli M, Proietti M, Geffers R, Traggiai E, Buer J, et al. ATP inhibits the generation and function of regulatory $\mathrm{T}$ cells through the activation of purinergic P2X receptors. Sci Signal (2011) 4(162):ra12. doi:10.1126/ scisignal.2001270
27. Szabo C, Pacher P. The outsiders: emerging roles of ectonucleotidases in inflammation. Sci Transl Med (2012) 4(146):146s14. doi:10.1126/ scitranslmed. 3004378

28. Erdmann AA, Gao ZG, Jung U, Foley J, Borenstein T, Jacobson KA, et al. Activation of Th1 and Tc1 cell adenosine A2A receptors directly inhibits IL-2 secretion in vitro and IL-2-driven expansion in vivo. Blood (2005) 105(12):4707-14. doi:10.1182/blood-2004-04-1407

29. Panther E, Idzko M, Herouy Y, Rheinen H, Gebicke-Haerter PJ, Mrowietz U, et al. Expression and function of adenosine receptors in human dendritic cells. FASEB J (2001) 15(11):1963-70. doi:10.1096/fj.01-0169com

30. Csóka B, Selmeczy Z, Koscsó B, Németh ZH, Pacher P, Murray PJ, et al. Adenosine promotes alternative macrophage activation via $\mathrm{A} 2 \mathrm{~A}$ and $\mathrm{A} 2 \mathrm{~B}$ receptors. FASEB J (2012) 26(1):376-86. doi:10.1096/fj.11-190934

31. Eltzschig HK, Thompson LF, Karhausen J, Cotta RJ, Ibla JC, Robson SC, et al. Endogenous adenosine produced during hypoxia attenuates neutrophil accumulation: coordination by extracellular nucleotide metabolism. Blood (2004) 104(13):3986-92. doi:10.1182/blood-2004-06-2066

32. Mandapathil M, Hilldorfer B, Szczepanski MJ, Czystowska M, Szajnik M, Ren J, et al. Generation and accumulation of immunosuppressive adenosine by human CD4+CD25highFOXP3+ regulatory T cells. J Biol Chem (2010) 285(10):7176-86. doi:10.1074/jbc.M109.047423

33. Zhou Q, Yan J, Putheti P, Wu Y, Sun X, Toxavidis V, et al. Isolated CD39 expression on CD4+ T cells denotes both regulatory and memory populations. Am J Transplant (2009) 9(10):2303-11. doi:10.1111/j.1600-6143.2009.02777.x

34. Deaglio S, Dwyer KM, Gao W, Friedman D, Usheva A, Erat A, et al. Adenosine generation catalyzed by CD39 and CD73 expressed on regulatory T cells mediates immune suppression. J Exp Med (2007) 204(6):1257-65. doi:10.1084/jem.20062512

35. Regateiro FS, Howie D, Nolan KF, Agorogiannis EI, Greaves DR, Cobbold SP, et al. Generation of anti-inflammatory adenosine by leukocytes is regulated by TGF- $\beta$. Eur J Immunol (2011) 41(10):2955-65. doi:10.1002/eji.201141512

36. Nikolova M, Carriere M, Jenabian MA, Limou S, Younas M, Kök A, et al. CD39/adenosine pathway is involved in AIDS progression. PLoS Pathog (2011) 7(7):e1002110. doi:10.1371/journal.ppat.1002110

37. Thammavongsa V, Kern JW, Missiakas DM, Schneewind O. Staphylococcus aureus synthesizes adenosine to escape host immune responses. J Exp Med (2009) 206(11):2417-27. doi:10.1084/jem.20090097

38. Smail EH, Cronstein BN, Meshulam T, Esposito AL, Ruggeri RW, Diamond RD. In vitro, Candida albicans releases the immune modulator adenosine and a second, high-molecular weight agent that blocks neutrophil killing. J Immunol (1992) 148(11):3588-95.

39. Clayton A, Al-Taei S, Webber J, Mason MD, Tabi Z. Cancer exosomes express CD39 and CD73, which suppress $\mathrm{T}$ cells through adenosine production. J Immunol (2011) 187(2):676-83. doi:10.4049/jimmunol.1003884

40. Stagg J, Divisekera U, McLaughlin N, Sharkey J, Pommey S, Denoyer D, et al. Anti-CD73 antibody therapy inhibits breast tumor growth and metastasis. Proc Natl Acad Sci U S A (2010) 107(4):1547-52. doi:10.1073/pnas. 0908801107

41. Gaspar HB, Aiuti A, Porta F, Candotti F, Hershfield MS, Notarangelo LD. How I treat ADA deficiency. Blood (2009) 114(17):3524-32. doi:10.1182/ blood-2009-06-189209

42. Giblett ER, Anderson JE, Cohen F, Pollara B, Meuwissen HJ. Adenosinedeaminase deficiency in two patients with severely impaired cellular immunity. Lancet (1972) 2(7786):1067-9. doi:10.1016/S0140-6736(72)92345-8

43. Haskó G, Linden J, Cronstein B, Pacher P. Adenosine receptors: therapeutic aspects for inflammatory and immune diseases. Nat Rev Drug Discov (2008) 7(9):759-70. doi:10.1038/nrd2638

44. Thompson LF, Eltzschig HK, Ibla JC, Van De Wiele CJ, Resta R, MoroteGarcia JC, et al. Crucial role for ecto-5'-nucleotidase (CD73) in vascular leakage during hypoxia. J Exp Med (2004) 200(11):1395-405. doi:10.1084/ jem.20040915

45. Leibovich SJ, Chen JF, Pinhal-Enfield G, Belem PC, Elson G, Rosania A, et al. Synergistic up-regulation of vascular endothelial growth factor expression in murine macrophages by adenosine A2A receptor agonists and endotoxin. Am J Pathol (2002) 160(6):2231-44. doi:10.1016/S0002-9440(10)61170-4

46. Eckle T, Krahn T, Grenz A, Kohler D, Mittelbronn M, Ledent C, et al. Cardioprotection by ecto-5'-nucleotidase (CD73) and A2B adenosine receptors. Circulation (2007) 115(12):1581-90. doi:10.1161/ CIRCULATIONAHA.106.669697 
47. Vilahur G, Gutiérrez M, Casani L, Varela L, Capdevila A, Pons-Lladó G, et al. Protective effects of ticagrelor on myocardial injury after infarction clinical perspective. Circulation (2016) 134(22):1708-19. doi:10.1161/ CIRCULATIONAHA.116.024014

48. Saldanha-Araujo F, Ferreira FIS, Palma PV, Araujo AG, Queiroz RHC, Covas DT, et al. Mesenchymal stromal cells up-regulate CD39 and increase adenosine production to suppress activated T-lymphocytes. Stem Cell Res (2011) 7(1):66-74. doi:10.1016/j.scr.2011.04.001

49. Ohta M, Toyama K, Gutterman DD, Campbell WB, Lemaître V, Teraoka R, et al. Ecto-5'-nucleotidase, CD73, is an endothelium-derived hyperpolarizing factor synthase. Arterioscler Thromb Vasc Biol (2013) 33(3):629-36. doi:10.1161/ATVBAHA.112.300600

50. Saze Z, Schuler PJ, Hong CS, Cheng D, Jackson EK, Whiteside TL. Adenosine production by human B cells and B cell-mediated suppression of activated T cells. Blood (2013) 122(1):9-18. doi:10.1182/blood-2013-02-482406

51. Pinhal-Enfield G, Ramanathan M, Hasko G, Vogel SN, Salzman AL, Boons GJ, et al. An angiogenic switch in macrophages involving synergy between toll-like receptors 2, 4, 7, and 9 and adenosine A2A receptors. Am J Pathol (2003) 163(2):711-21. doi:10.1016/S0002-9440(10)63698-X

52. Deng W, Chen W, Zhang Z, Huang S, Kong W, Sun Y, et al. Mesenchymal stem cells promote CD206 expression and phagocytic activity of macrophages through IL-6 in systemic lupus erythematosus. Clin Immunol (2015) 161(2):209-16. doi:10.1016/j.clim.2015.07.011

53. Kim J, Hematti P. Mesenchymal stem cell-educated macrophages: a novel type of alternatively activated macrophages. Exp Hematol (2009) 37(12):1445-53. doi:10.1016/j.exphem.2009.09.004

54. Eichin D, Laurila JP, Jalkanen S, Salmi M. CD73 activity is dispensable for the polarization of M2 macrophages. PLoS One (2015) 10(8):e0134721. doi:10.1371/journal.pone.0134721

55. Fischer UM, Harting MT, Jimenez F, Monzon-Posadas WO, Xue H, Savitz SI, et al. Pulmonary passage is a major obstacle for intravenous stem cell delivery: the pulmonary first-pass effect. Stem Cells Dev (2009) 18(5):683-92. doi:10.1089/scd.2008.0253

56. Eggenhofer E, Benseler V, Kroemer A, Popp FC, Geissler EK, Schlitt HJ, et al. Mesenchymal stem cells are short-lived and do not migrate beyond the lungs after intravenous infusion. Front Immunol (2012) 3:297. doi:10.3389/ fimmu.2012.00297

57. Liu XB, Chen H, Chen HQ, Zhu MF, Hu XY, Wang YP, et al. Angiopoietin-1 preconditioning enhances survival and functional recovery of mesenchymal stem cell transplantation. JZhejiang Univ Sci B (2012) 13(8):616-23. doi:10.1631/jzus.B1201004

58. Lee RH, Pulin AA, Seo MJ, Kota DJ, Ylostalo J, Larson BL, et al. Intravenous hMSCs improve myocardial infarction in mice because cells embolized in lung are activated to secrete the anti-inflammatory protein TSG-6. Cell Stem Cell (2009) 5(1):54-63. doi:10.1016/j.stem.2009.05.003
59. Soleymaninejadian E, Pramanik K, Samadian E. Immunomodulatory properties of mesenchymal stem cells: cytokines and factors. Am J Reprod Immunol (2012) 67(1):1-8. doi:10.1111/j.1600-0897.2011.01069.x

60. Yegutkin GG, Samburski SS, Jalkanen S. Soluble purine-converting enzymes circulate in human blood and regulate extracellular ATP Level via counteracting pyrophosphatase and phosphotransfer reactions. FASEB J (2003) 17(10):1328-30. doi:10.1096/fj.02-1136fje

61. Airas L, Niemelä J, Salmi M, Puurunen T, Smith DJ, Jalkanen S. Differential regulation and function of CD73, a glycosyl-phosphatidylinositol-linked 70-kD adhesion molecule, on lymphocytes and endothelial cells. J Cell Biol (1997) 136(2):421-31. doi:10.1083/jcb.136.2.421

62. Maksimow M, Kyhälä L, Nieminen A, Kylänpää L, Aalto K, Elima K, et al. Early prediction of persistent organ failure by soluble CD73 in patients with acute pancreatitis*. Crit Care Med (2014) 42(12):2556-64. doi:10.1097/ CCM.0000000000000550

63. Amarnath S, Foley JE, Farthing DE, Gress RE, Laurence A, Eckhaus MA, et al. Bone marrow derived mesenchymal stromal cells harness purinergenic signaling to tolerize human Th1 cells in vivo. Stem Cells (2014) 33(4):1-18. doi:10.1002/stem.1934

64. Bönner F, Borg N, Burghoff S, Schrader J. Resident cardiac immune cells and expression of the ectonucleotidase enzymes CD39 and CD73 after ischemic injury. PLoS One (2012) 7(4):e34730. doi:10.1371/journal.pone.0034730

65. Groh ME, Maitra B, Szekely E, Koç ON. Human mesenchymal stem cells require monocyte-mediated activation to suppress alloreactive $\mathrm{T}$ cells. Exp Hematol (2005) 33(8):928-34. doi:10.1016/j.exphem.2005.05.002

66. Lu W, Xie ZY, Tang Y, Bai L, Yao Y, Fu C, et al. Photoluminescent mesoporous silicon nanoparticles with siCCR2 improve the effects of mesenchymal stromal cell transplantation after acute myocardial infarction. Theranostics (2015) 5(10):1068-82. doi:10.7150/thno.11517

67. Horenstein AL, Chillemi A, Zaccarello G, Bruzzone S, Quarona V, Zito A, et al. A CD38/CD203a/CD73 ectoenzymatic pathway independent of CD39 drives a novel adenosinergic loop in human T lymphocytes. Oncoimmunology (2013) 2(9):e26246. doi:10.4161/onci.26246

Conflict of Interest Statement: The authors declare that the research was conducted in the absence of any commercial or financial relationships that could be construed as a potential conflict of interest.

Copyright (c) 2017 Monguió-Tortajada, Roura, Gálvez-Montón, Franquesa, BayesGenis and Borràs. This is an open-access article distributed under the terms of the Creative Commons Attribution License (CC BY). The use, distribution or reproduction in other forums is permitted, provided the original author(s) or licensor are credited and that the original publication in this journal is cited, in accordance with accepted academic practice. No use, distribution or reproduction is permitted which does not comply with these terms. 